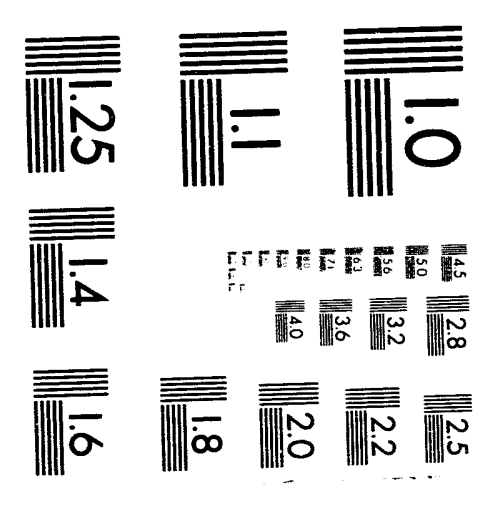



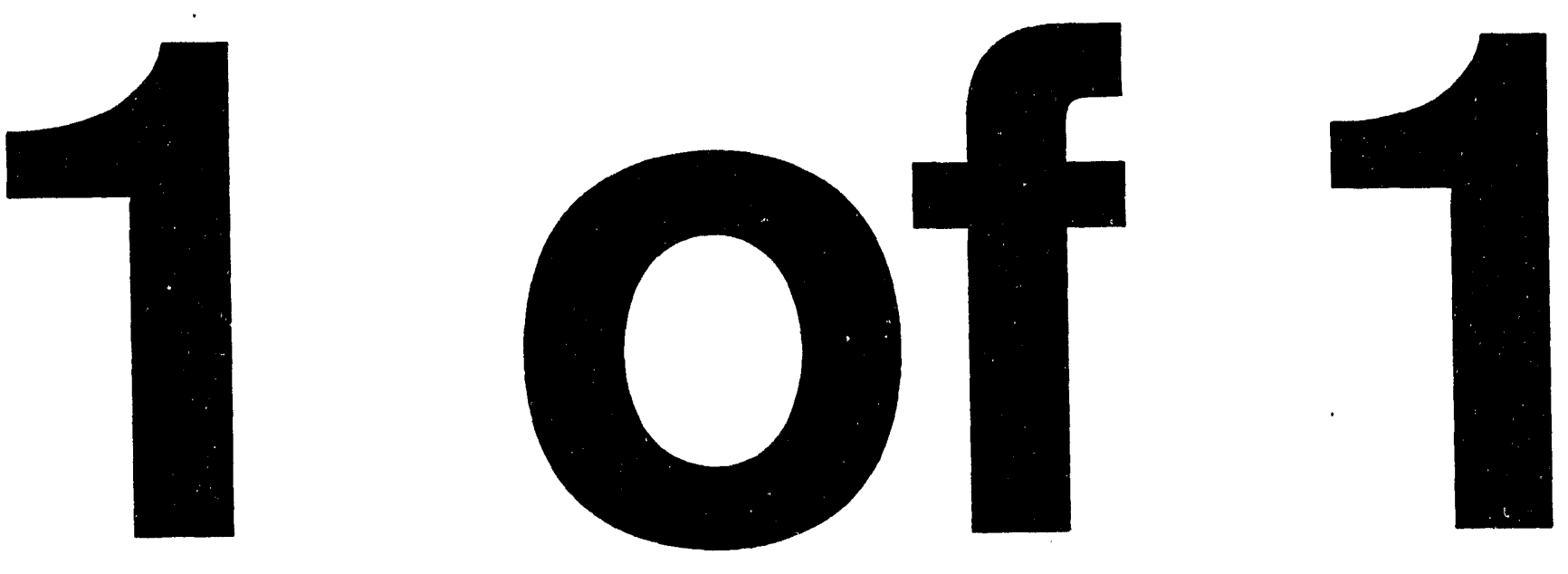


\title{
Energy Storage Specification Requirements For Hybrid-Electric Vehicles
}

\author{
A. F. Burke \\ September 1993 \\ Idaho National Engineering Laboratory \\ EG\&G Idaho, Inc. \\ Idaho Falls, Idaho 83415
}

Prepared for the

U.S. Department of Energy

Assistant Secretary for Energy Efficiency and Renewable Energy (EE)

Under DOE Idaho Operations Office

Contract DE-AC07-76ID01570

\section{MASTER}




\section{ABSTRACT}

A study has been made of energy storage unit requirements for hybridelectric vehicles. The drivelines for these vehicles included both primary energy storage units and/or pulse power units. The primary energy storage units were sized to provide "primary energy" ranges up to $60 \mathrm{~km}(38 \mathrm{mi})$. The total power capability of the drivelines were such that the vehicles had 0 to $96 \mathrm{~km} / \mathrm{h}$ ( 0 to $60 \mathrm{mph}$ ) acceleration times of 10 to $12 \mathrm{~s}$. The results of the study are displayed as a Ragone plot-peak power density ( $\mathrm{W} / \mathrm{kg}$ ) versus useable energy density $(W \cdot h / k g)$-and as a list of specifications for the energy storage units.

In general, the power density requirements for primary energy storage devices to be used in hybrid vehicles are much higher than that for devices to be used in electric vehicles. The energy density and power density requirements for pulse-power devices for hybrid vehicles, including engineelectric vehicles, are not much different than those to be used to load-level the battery in an electric vehicle.

The cycle life requirements $(1,000$ to 2,000$)$ for primary energy-storage units for hybrid vehicles are about double that for electric vehicles, because of the reduced size of the storage units in the hybrid vehicles. The cycle life $(100,000)$ for pulse-power devices for hybrid vehicles is about the same as for electric vehicles having battery load leveling.

Because of the need for additional components in the hybrid driveline, the cost of the energy storage units in hybrid vehicles should be much less (at least a factor of two) than those in electric vehicles. Based on the energy storage capacity of the individual energy storage units, this will be the case if the specific cost of the primary energy-storage units is $\$ 200 / \mathrm{kW} \cdot \mathrm{h}$ and that of the pulse power units is $\$ 1 / \mathrm{W} \cdot \mathrm{h}$.

There are no presently available energy storage units that meet all the specifications for hybrid vehicle applications, but ultracapacitors and bipolar lead-acid batteries are under development that have the potential for meeting them if the program design goals are met. If flywheel systems having a mechanical system energy density of 40 to $50 \mathrm{~W} \cdot \mathrm{h} / \mathrm{kg}$ and an electrical system power density of 2 to $3 \mathrm{~kW} / \mathrm{kg}$ can be developed, the flywheel system also would have the potential of meeting the hybrid vehicle energy storage specifications for primary storage and pulse power units. 


\section{CONTENTS}

Abstract ......................... . . $\mathbf{i}$. . $\mathbf{i}$

Introduction . . . . . . . . . . . . . . . . . . . . . . 1

Scope of the Study and Objectives ................ 3

Approach . . . . . . . . . . . . . . . . . . . . . 5

Vehicles . . . . . . . . . . . . . . . . 5

Driveline Configurations . . . . . . . . . . . . . . . 5

Energy Storage Options . . . . . . . . . . . . . . . . 10

Method of Analysis . . . . . . . . . . . . . . . 11

Summary of Results . . . . . . . . . . . . . . . . . . . . 13

Unassisted Primary Energy Storage . . . . . . . . . . . . . 13

Pulsed Power Energy Storage . . . . . . . . . . . . . 13

Energy Storage Unit Specifications . . . . . . . . . . . . . . . . . . . 19

Primary Energy Storage Unit (without a pulse-power unit) . . . . . 19

Pulse Power Energy Storage . . . . . . . . . . . . . . . 23

Comparison of the Specifications with the Characteristics of

Various Energy Storage Technologies . . . . . . . . . . . . . . . . 27

Cycle Life and Cost Considerations . . . . . . . . . . . . . . . 31

Conclusions .. . . . . . . . . . . . . . . . . . . . 33

References . . . . . . . . . . . . . . . . . . . . 35

\section{FIGURES}

1-A. Electric and series hybrid vehicle driveline configurations . . . 8

1-B. Parallel hybrid driveline schematics . . . . . . . . . . . . 9

1-C. Engine-electric driveline schematic using ultracapacitors . . . . 9

2. Lotus 1-2-3 spreadsheet output for hybrid vehicle calculations . . 12

3-A. Peak-power-density requirements for the primary energy storage. unit in a compact car without a pulse-power unit. . . . . . . . . 14

3-B. Peak-power requirements for the primary-energy-storage unit on a minivan without a pulse-power unit . . . . . . . . . . . . 15

4-A. Peak-power-density requirement for a pulse-power unit in a compact car 
4-B. Peak-power-density requirement for a pulse-power unit in a minivan . . . . . . . . . . . . . . . . . 18

5-A. Average discharge-power-density for different driving modes for a minivan . . . . . . . . . . . . . . . . . 21

5-B. Average discharge-power-density for different driving modes for a compact car . . . . . . . . . . . . . . . . . 22

6. Ragone plot for primary-energy-storage and pulse-power units . . 28

\section{TABLES}

1. Baseline hybrid vehicle characteristics . . . . . . . . . . 6

2. Hybrid vehicle power requirements and energy consumption for various driving modes . . . . . . . . . . . . . . . . . 6

3. Weight correction factors . . . . . . . . . . . . . . . 7

4. Hybrid vehicle energy storage specifications . . . . . . . . . 20

5. Grades in the Los Angeles Basin and corresponding power and energy requirements at $88 \mathrm{~km} / \mathrm{h}(55 \mathrm{mph})$. . . . . . . . . . . . . . . 24

6. Power requirements and length of grade sustainable at $88 \mathrm{~km} / \mathrm{h}$ ( $55 \mathrm{mph}$ ) using pulse unit energy storage . . . . . . . 24 


\section{Energy Storage Specification Requirements For Hybrid-Electric Vehicles}

\section{INTRODUCTION}

There is a wide range of driveline design options possible for hytrid-electric vehicles ${ }^{1,2}$ depending on the primary objective of the design. Energy storage devices are key elements in all the designs. In some designs, they are the on-board source of both the energy and the power required to propel the vehicle. In other designs, their primary function is to load level the engine or fuel cell, which is converting a chemical fuel to mechanical or electrical energy to power the vehicle. It can be expected that the design requirements for energy storage devices serving different roles in the powertrain (driveline) would vary a great deal. In addition, the design requirements will depend on the size and the performance specifications of the vehicle in which they are to be used. A study of energy storage specification requirements for devices to be used in various types of hybrid-electric vehicles has recently been completed at the Idaho National Engineering Laboratory (INEL). The results of that study and their significance relative to the U.S. Department of Energy (DOE) Hybrid Vehicle Program are discussed in this report. 


\section{SCOPE OF THE STUDY AND OBJECTIVES}

The study was intended to determine design specifications for energy storage devices to be used in hybrid-electric vehicles without focusing on specific types of devices, such as batteries, ultracapacitors, or fly-wheels. The intent was thus to be technology neutral. This meant that primary attention was given to the energy storage $(\mathrm{kW} \cdot \mathrm{h})$ and power $(\mathrm{KW})$ requirements for typical vehicle designs and the resultant energy density ( $\mathrm{W} / \mathrm{h} / \mathrm{kg}$ and $W \cdot h / L)$ and peak power density $(W / k g)$ requirements for devices to be used in the vehicle drivelines. The effect of vehicle performance (acceleration time and range) on energy storage requirements was studied for a number of different hybrid driveline configurations (series, parallel, and engine-electric). Determination of the effect of vehicle performance and driveline configuration on the specifications for the energy storage devices was included in the study. 


\section{APPROACH}

\section{Vehicles}

Two types of vehicles were considered in this study - compact passenger cars and minivans. The baseline characteristics used in the vehicle simulation calculations are given in Table 1. The baseline weights shown are curb weight plus $136 \mathrm{~kg}$ (300 lbs) and do not include other loads. The vehicle power requirements $(\mathrm{kW} / \mathrm{kg})$ veh and the energy consumption $(\mathrm{W} \cdot \mathrm{h} / \mathrm{km})$ for various driving modes were calculated using SIMPLEV. SIMPLEV is the electric/hybrid vehicle simulation program developed at the Idaho National Engineering Laboratory. ${ }^{3}$ Results for the baseline vehicles are summarized in Table 2 for 0 to $96 \mathrm{~km} / \mathrm{h}$ ( 0 to $60 \mathrm{mph}$ ) accelerations, the Federal Urban and Highway cycles, a cruise speed of $105 \mathrm{~km} / \mathrm{h}(65 \mathrm{mph})$ on level ground, and $88 \mathrm{~km} / \mathrm{h}$ (55 mph) on a $6 \%$ grade. Six percent is the maximum grade on the interstate highway system even in mountainous areas. Most of the values given in Table 2 depend on vehicle weight and thus they are affected by changes in the vehicle weight due to changes in the weights of the energy storage units. The correction factors, determined from a series of SIMPLEV runs at different vehicle weights, are given in Table 3. These factors are used in the later analyses of the hybrid-electric vehicles.

\section{Driveline Configurations}

There are several driveline configurations of interest (see Figure 1) for the development of hybrid vehicles. The series and parallel configurations (Figures $1-A$ and 1-B) have a battery or a flywheel (primary energy storage) for on-board storage of energy and thus, if desired, can be operated on that energy alone for some distance-designated as the "primary energy" range of the hybrid vehicle. The engine in the series and parallel configurations can be used to generate power during periods of high power demand and to recharge the primary energy storage unit during periods of low power demand. In the case of the engine-electric configuration (Figure $1-C$ ), there is no primary energy storage unit (battery or flywheel) and the energy 
Table 1. Baseline hybrid vehicle characteristics.

\begin{tabular}{||c|c|c|}
\hline Characteristic & Compact Car & Minivan \\
\hline Test weight $(\mathrm{kg})$ & 1,227 & 1,727 \\
\hline Drag coefficient & 0.22 & 0.32 \\
\hline Frontal area $\left(\mathrm{m}^{2}\right)$ & 1.765 & 2.60 \\
\hline Rolling resistance & 0.005 & 0.007 \\
\hline $\begin{array}{c}\text { Acceleration time }(\mathrm{sec}) \\
0 \text { to } 96 \mathrm{~km} / \mathrm{h}\end{array}$ & 10 to 12 & 10 to 12 \\
\hline Range (km) \\
FUDS
\end{tabular}

Table 2. Hybrid vehicle power requirements and energy consumption for various driving modes.

\begin{tabular}{|c|c|c|c|c|}
\hline \multicolumn{5}{|c|}{ Peak Power Requirements } \\
\hline \multicolumn{5}{|c|}{ Driving Mode } \\
\hline \multicolumn{3}{|c|}{$\begin{array}{c}\text { Times (sec), Maximum Effort Acceleration } \\
(0-96 \mathrm{~km} / \mathrm{hr})\end{array}$} & \multicolumn{2}{|c|}{$\begin{array}{l}(\mathrm{kW} / \mathrm{kg}) \text { vehicle } \\
\text { (based on vehicle weight) }\end{array}$} \\
\hline \multicolumn{3}{|c|}{8} & \multicolumn{2}{|c|}{0.10} \\
\hline \multicolumn{3}{|c|}{10} & \multicolumn{2}{|c|}{0.07} \\
\hline \multicolumn{3}{|c|}{12} & \multicolumn{2}{|c|}{0.0475} \\
\hline \multicolumn{3}{|c|}{15} & \multicolumn{2}{|c|}{0.036} \\
\hline \multicolumn{3}{|l|}{ FUDS cycle } & \multicolumn{2}{|c|}{0.027} \\
\hline \multicolumn{2}{|l|}{ FHTS cycle } & & \multicolumn{2}{|c|}{0.022} \\
\hline \multicolumn{5}{|c|}{ Average Power Requirements and Energy Consumption } \\
\hline & \multicolumn{2}{|c|}{ Compact Car } & \multicolumn{2}{|c|}{ Minivan } \\
\hline Driving Mode & $(\mathrm{kW} / \mathrm{kg})$ veh & $W h / k m$ & $(\mathrm{~kW} / \mathrm{kg})$ veh & $W h / k m$ \\
\hline $105 \mathrm{~km} / \mathrm{h}$ & 0.0080 & 94 & 0.0122 & 201 \\
\hline $88 \mathrm{~km} / \mathrm{h}$ & 0.0056 & 78 & 0.0079 & 155 \\
\hline FUDS cycle & 0.0026 & 100 & 0.0032 & 176 \\
\hline FHTS cycle & 0.0051 & 81 & 0.0072 & 160 \\
\hline $88 \mathrm{~km} / \mathrm{h}$ on $3 \%$ & 0.0144 & 200 & 0.0167 & 326 \\
\hline $88 \mathrm{~km} / \mathrm{h}$ on $6 \%$ & 0.0223 & 311 & 0.0236 & 462 \\
\hline
\end{tabular}


Table 3. Weight correction factors.

\begin{tabular}{|c|c|c|}
\hline \multicolumn{3}{|c|}{ Energy Use } \\
\hline & Cycle & $a^{d}$ \\
\hline & FUDS & 0.66 \\
\hline & FHTS & 0.37 \\
\hline & $105 \mathrm{~km} / \mathrm{h}$ & 0.0 \\
\hline & $88 \mathrm{~km} / \mathrm{h}$ at $3 \%$ & 0.68 \\
\hline \multicolumn{3}{|c|}{ Maximum Power } \\
\hline & FUDS & 0.90 \\
\hline & FHTS & 0.85 \\
\hline & $105 \mathrm{~km} / \mathrm{h}$ & 0.0 \\
\hline & $88 \mathrm{~km} / \mathrm{h}$ at $3 \%$ & 0.68 \\
\hline \multicolumn{3}{|c|}{ d. $\quad \frac{V}{V_{0}}=1+a\left(\frac{W}{W_{0}}-1\right)$} \\
\hline $\begin{array}{l}V \\
V_{0} \\
w_{0}\end{array}$ & $\begin{array}{l}=\text { selected parameter } \\
=\text { value of parameter for } W=W_{0} \\
=\text { baseline weight of the hybrid }\end{array}$ & vehicle \\
\hline
\end{tabular}


Schematic of a series hybrid driveline.

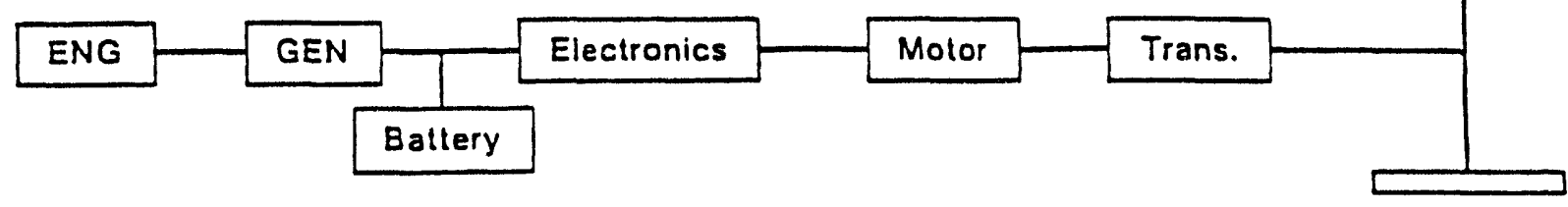

Schematic of an electirc vehicle propulsion system, including battery load leveling.

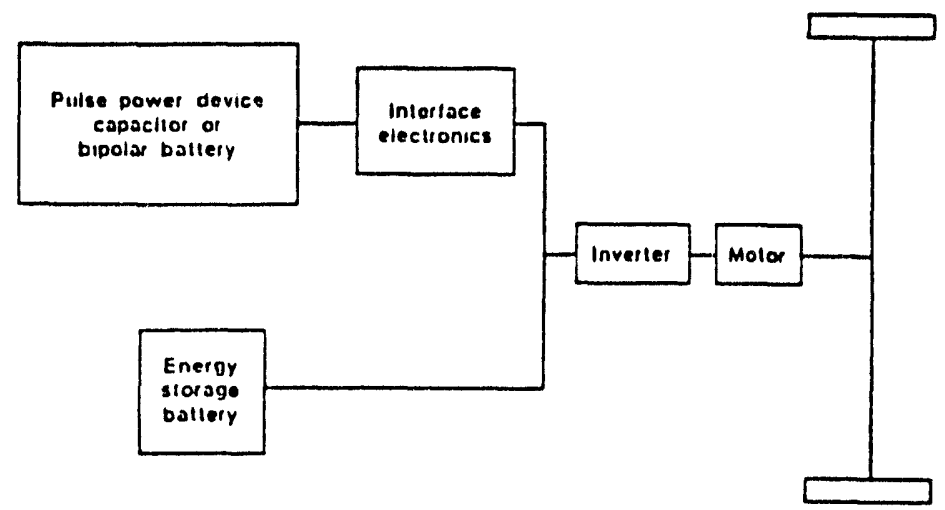

Figure 1-A. Electric and series hybrid vehicle driveline configurations. 


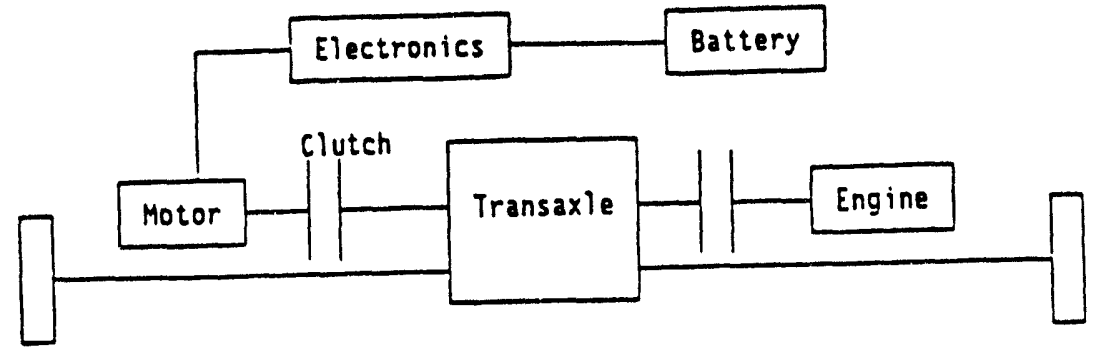

Figure 1-B. Schematic of a single-shaft parallel hybrid driveline.

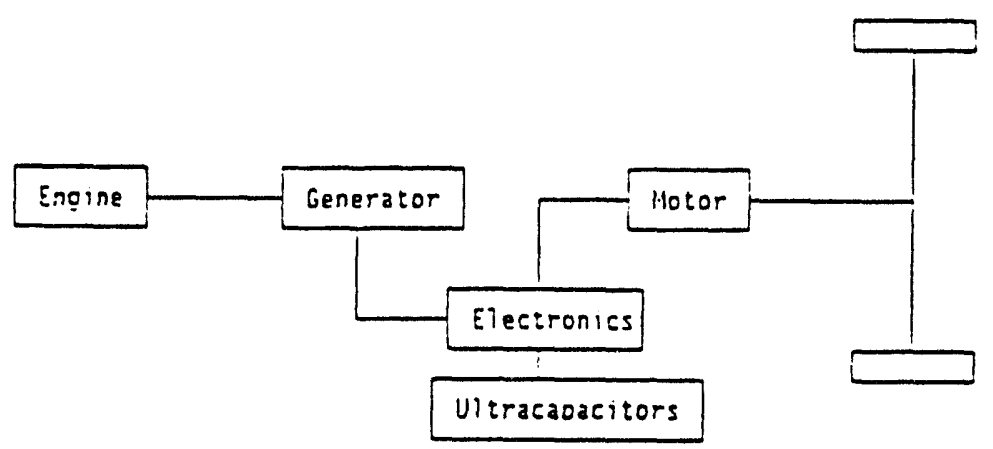

Figure 1-C. Schematic of an engine-electric hybrid driveline using ultracapacitors. 
storage unit (secondary energy storage) in the driveline is used to load level the engine by supplying pulse power during short periods of high power demand. In this case, all the electrical energy to power the vehicle is produced on-board by the engine from a chemical fuel. The engine-electric vehicle has a zero primary energy range.

\section{Energy Storage Options}

As shown in Figure 1, energy storage units are used to perform a number of different functions in hybrid vehicle drivelines. Their two main functions are to store a non-fuel energy (primary energy) on-board the vehicle and/or to provide pulse power during short periods of peak power demand. The energy storage unit (battery or flywheel) that stores non-fuel energy obtained from an off-board source is termed the primary energy storage unit as it is the primary source of energy to propel the vehicle. As a minimum, this unit must be sized to store the energy needed to provide the primary energy range of the vehicle. It would also be desirable for the primary energy storage unit to provide the peak power during periods of maximum acceleration. If this is not possible without significantly reducing the cycle life of the primary storage unit or would require a much larger or heavier unit than needed to store the primary energy, then a second energy storage unit can be used to provide the pulse power during periods of igh power demand. This second unit is termed a secondary energy, or pulse power, storage unit. It is sized to store sufficient energy that it can meet the peak power demands during a prescribed driving cycle without being discharged below a specified minimum state-of-charge. To be an attractive component for use in a hybrid driveline, the pulse power unit must have a very high peak power density and an energy density sufficiently high that it is much smaller and lighter than the primary energy storage unit or the engine in the case of the engine-electric configuration. 


\section{Method of Analysis}

The approach utilized to determine the characteristics required of energy storage units to be used in hybrid-electric vehicles involved the use of the SIMPLEV and ULTRACAP simulation programs..$^{3,4}$ The SIMPLEV program was used to calculate the maximum and average power requirements (see Table 2) for the various driving modes of interest. The ULTRACAP program was used to determine the minimum energy storage requirement $(W \cdot h)$ for the pulse power unit for load leveling the primary energy storage unit or the engine on the Federal Urban and Highway cycles. The vehicle simulation results permit the sizing ( $K w \cdot h$ and $K w$ ) of the primary and pulse power energy storage units and the engine in the various hybrid drivel ine configurations. The weight, volume, and peak power density characteristics of the primary and pulse power energy storage units are then calculated using a Lotus 1-2-3 spreadsheet as shown in Figure 2. A separate spreadsheet is used for the compact cars and minivans. The inputs to the calculations are given on the left side of the sheet and the calculated values are shown on the right side. As indicated in Figure 2, each sheet includes the calculations for 0 to $60 \mathrm{mph}$ acceleration times of $8,10,12$, and 15 seconds. The effects of the weight changes from the baseline values for each of the vehicies are calculated by iteration (the F-9 key in Lotus). Note from Figure 2 that the energy densities of the primary and pulse power energy storage units are considered as input values along with the primary energy range of the vehicle. The calculated characteristics of the energy storage units are presented in the next section as functions of these input values. 


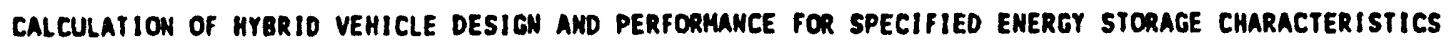
IOR A MINIVAN

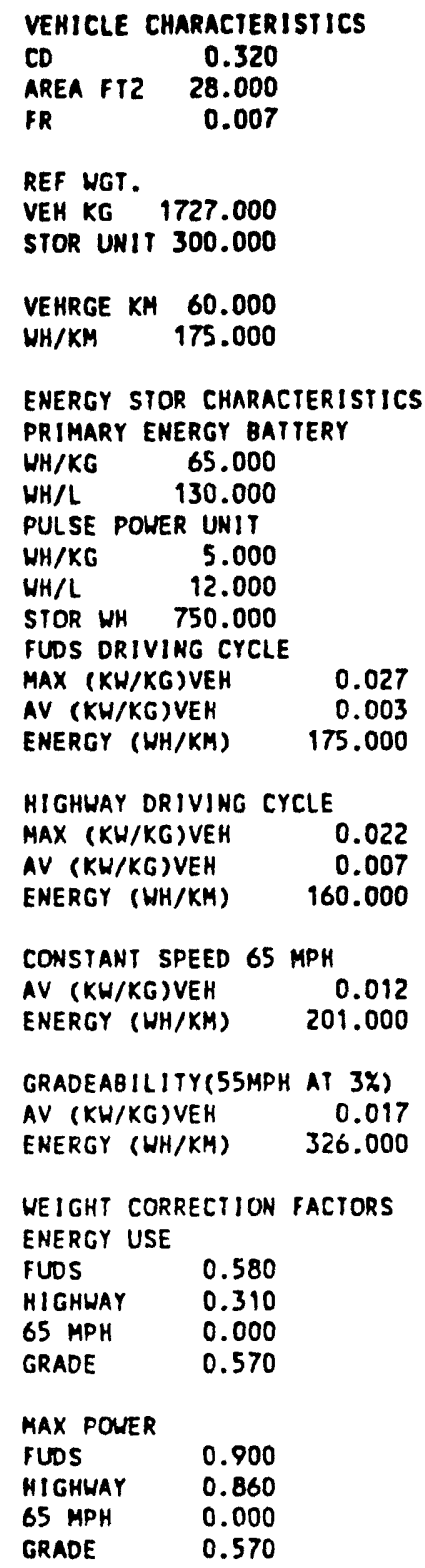

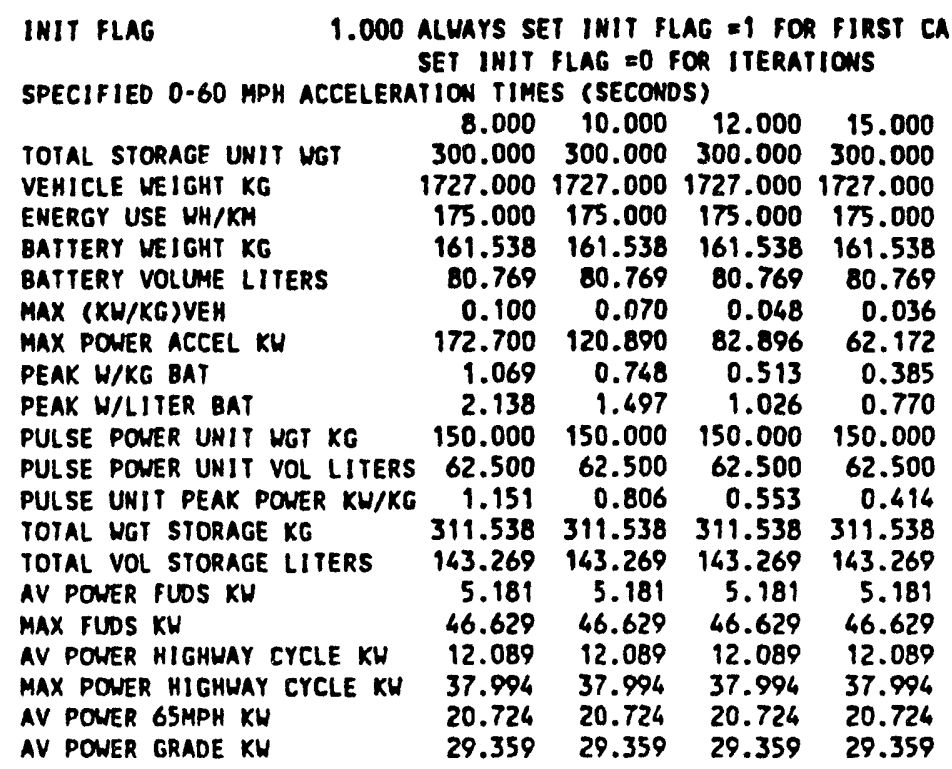

Figure 2. Sample of Lotus 1-2-3 spreadsheet output for hybrid vehicle calculations. 


\section{SUMMARY OF RESULTS}

\section{Unassisted Primary Energy Storage}

One approach to designing a hybrid-electric driveline is to provide all the power to accelerate the vehicle from the primary energy storage unit. In this case, the unit is sized by the "primary energy" range of the vehicle and the peak power density is calculated from the maximum power required. The peak power density requirements for the compact car and minivan for ranges of 32 and $60 \mathrm{~km}$ and 0 to $60 \mathrm{mph}$ acceleration times of 10 and 15 seconds are shown in Figures $3-A$ and $3-B$. If a primary energy storage unit (battery or flywhee1) with a particular energy density-(W/h/ $\mathrm{kg})$ prim-has a peak power density of less than the value given in Figure 3 , the unit will be sized by the peak power demand and thus be larger than that required to meet only the energy storage requirement. The peak power density requirement increases markedly as the energy density of the primary energy storage unit is increased and the vehicle acceleration time and "primary energy" range are reduced. For the most part, the peak power requirements are much greater than those of available batteries : $W / \mathrm{kg}$ between 100 and 200) or the goals for advance batteries ( $\mathrm{W} / \mathrm{kg}$ between 200 and 400 ). The peak power density requirements would be reduced only slightly (by at most $25 \%$, if the engine is sized for the high-speed cruise power requirements) if the engine is used to provide part of the power during periods of maximum power demand, because it is unlikely that the engine in a hybrid vehicle would be sized to meet a large fraction of the power required during maximum effort accelerations.

\section{Pulsed Power Energy Storage}

Since, as shown in the previous section, the peak power requirements can be very high for an unassisted primary energy storage unit in many hybrid vehicle designs, it is reasonable to consider an energy storage system in which the energy required to meet the "primary energy" range is provided by a primary energy storage unit and the pulse power is provided by a pulse power energy storage unit. In this system, it would be expected that the pulse 


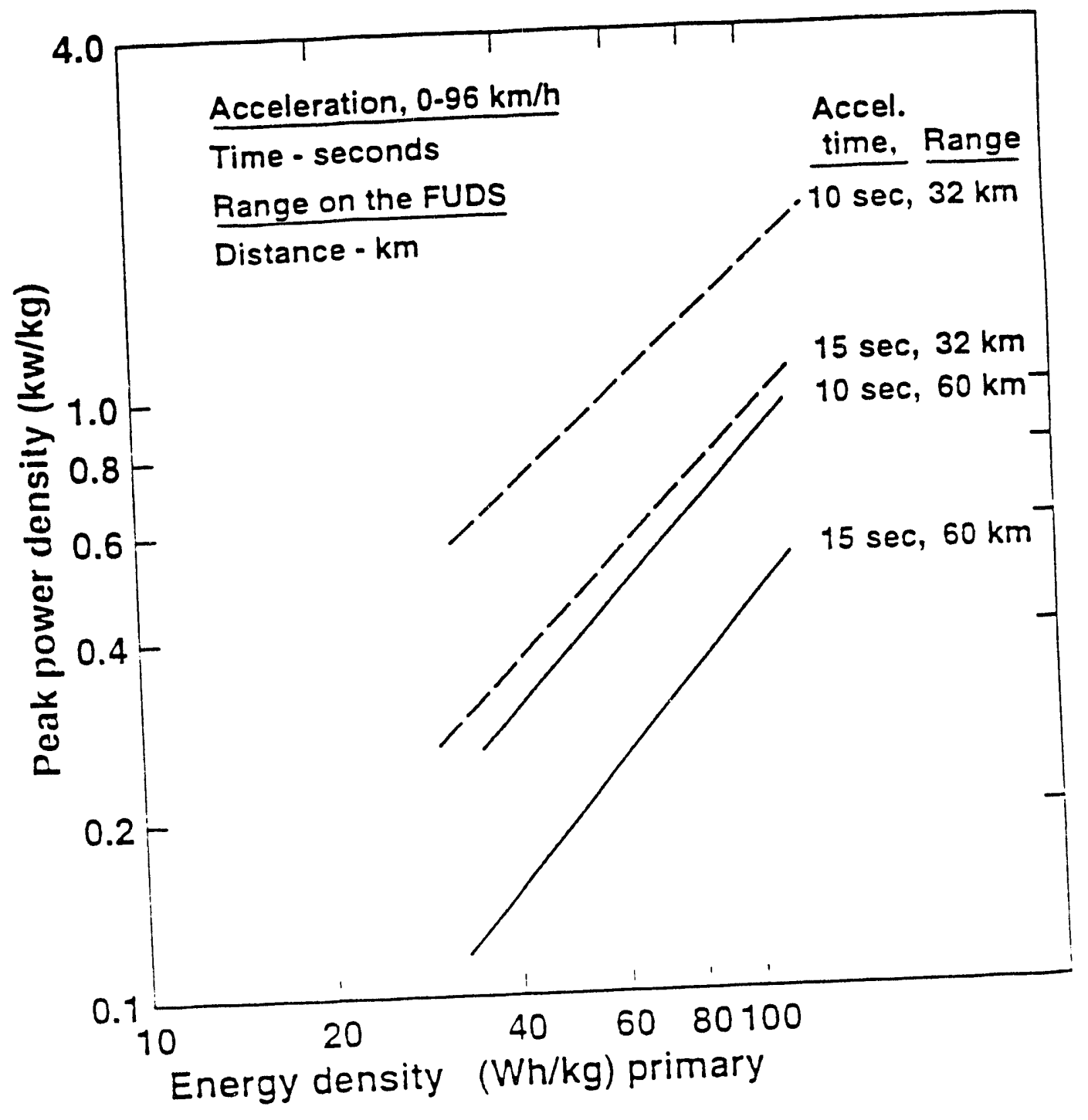

Figure 3-A. Peak-power-density requirements for the primary energy storage unit in a compact car without a pulse power unit. 


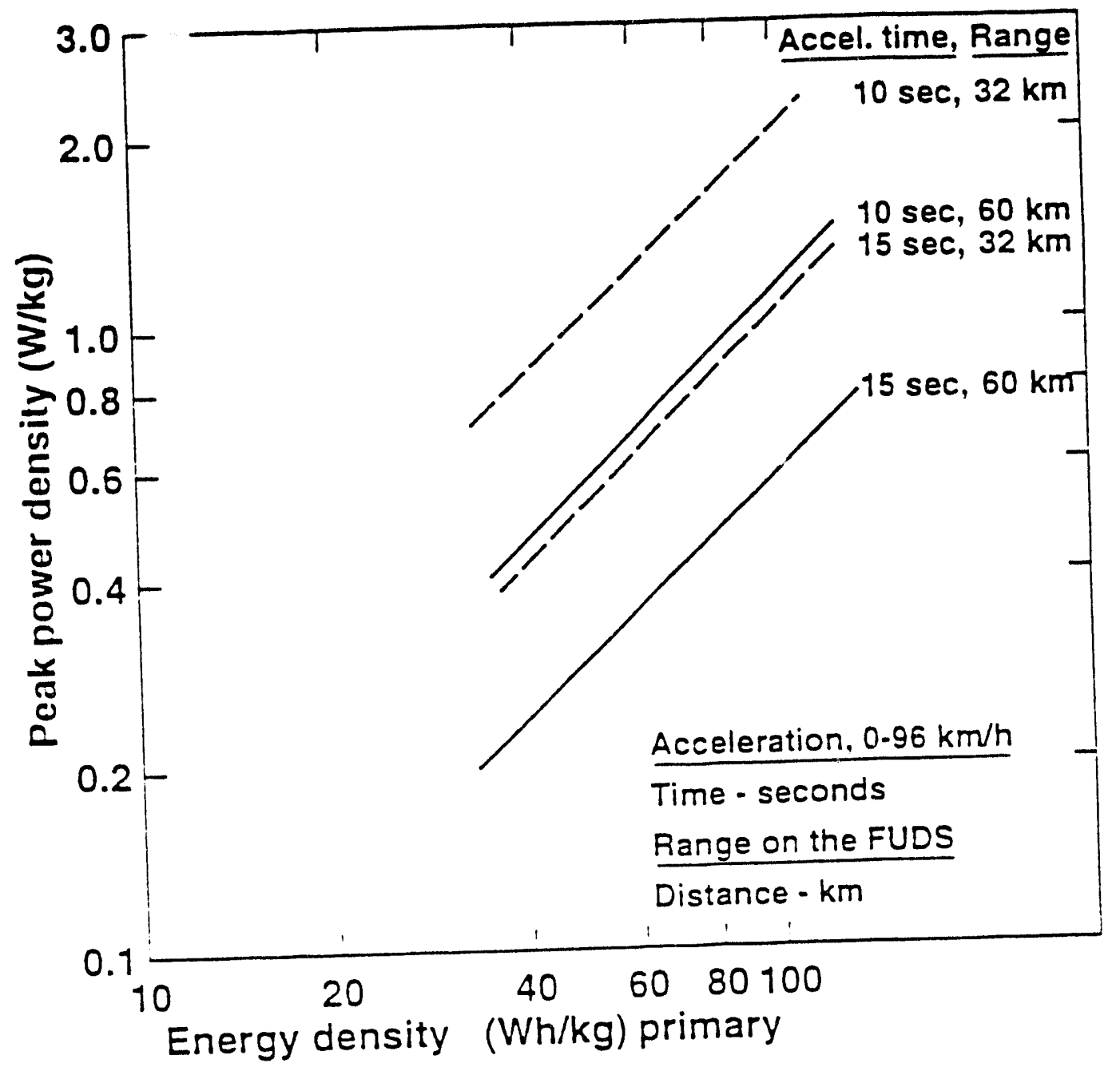

Figure 3-B. Peak-power requirements for the primary-energy-storage unit on a minivan without a pulse power unit. 
unit would be much smaller and lighter than the primary unit. Results for the peak power density requirements for the pulso power units are given in Figures 4-A and 4-B for the compact car and the minivan. The pulse power units in the compact car were sized to store $500 \mathrm{Wh}$ and those in the minivan were sized to store $750 \mathrm{~W} \cdot \mathrm{h}$. Results are given for pulse power units having an energy density of 5 to $15 \mathrm{~W} \cdot \mathrm{h} / \mathrm{kg}$. The peak power density requirements for the pulse power unit increase rapidly with its energy density being 0.5 to $1 \mathrm{~kW} / \mathrm{kg}$ for an energy density of $5 \mathrm{~W} \cdot \mathrm{h} / \mathrm{kg}$ and 1 to $3 \mathrm{~kW}$ for $15 \mathrm{~W} \cdot \mathrm{h} / \mathrm{kg}$. 


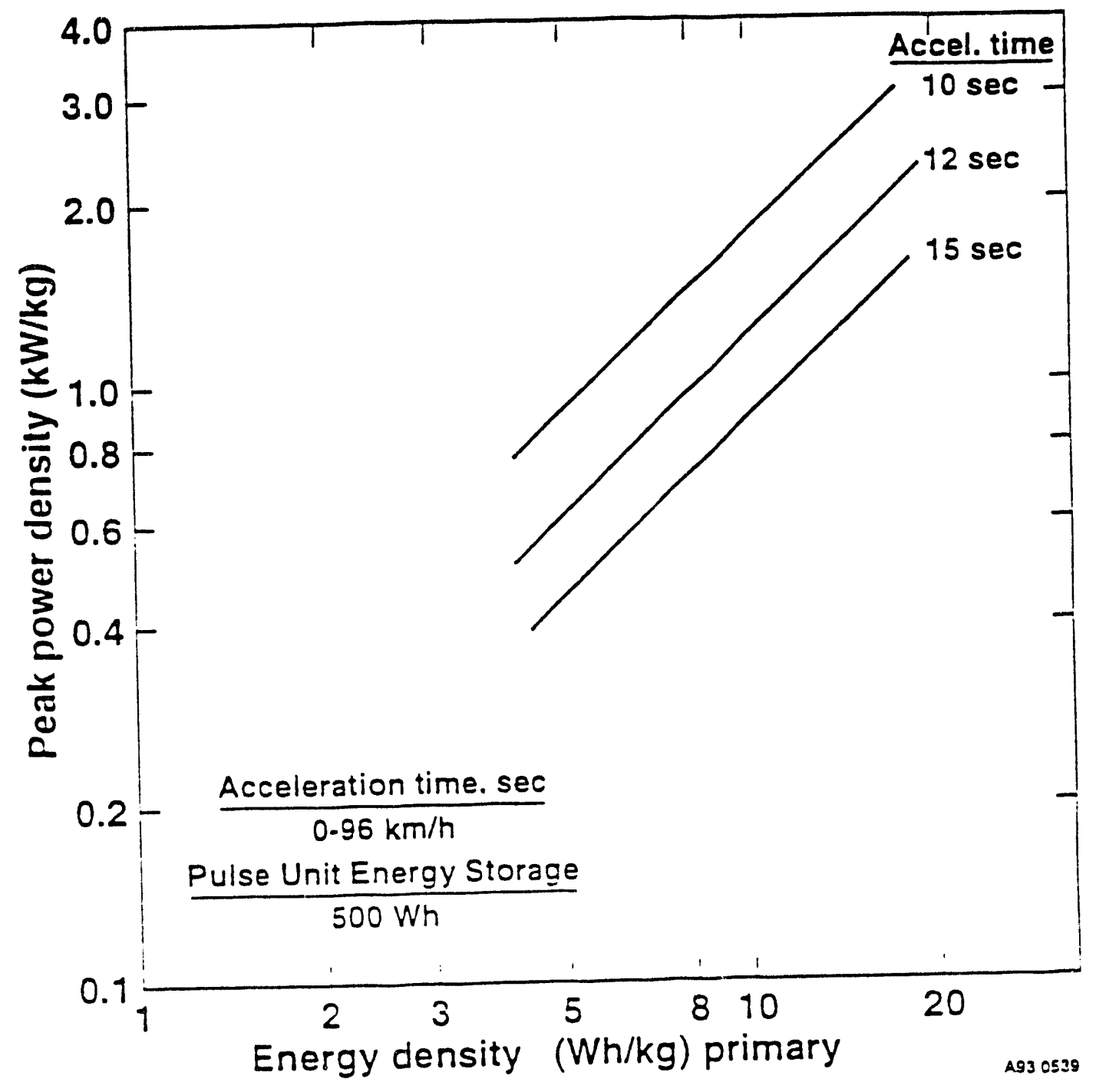

Figure 4-A. Peak-power density requirement for a pulse-power unit in a compact car. 


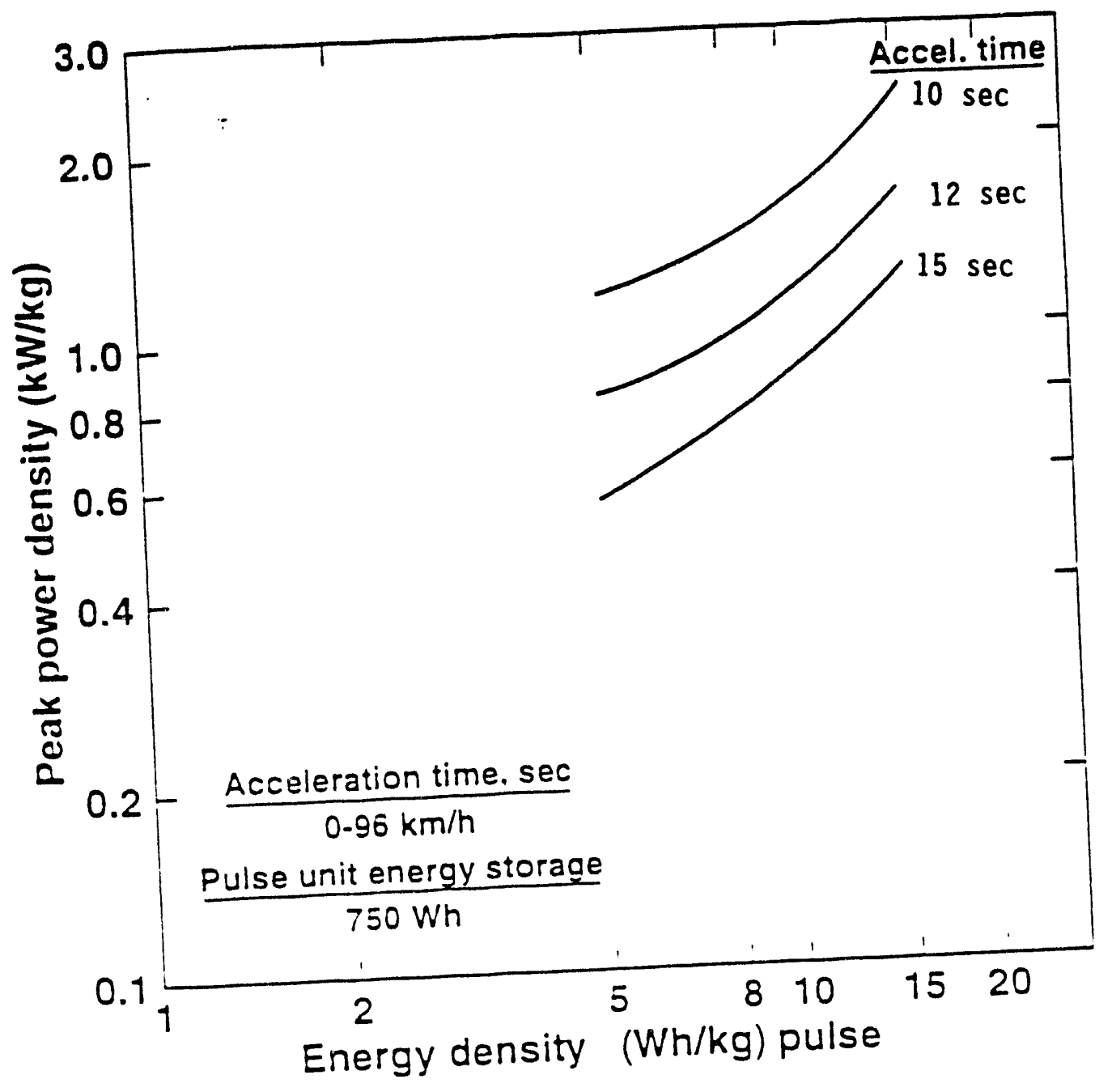

Figure 4-B. Peak-power-density requirement for a pulse-power unit in a minivan. 


\title{
ENERGY STORAGE UNIT SPECIFICATIONS
}

\author{
Primary Energy Storage Units \\ (without a pulse power unit)
}

Specifications for primary energy storage units without pulse power assist are given in Table 4 . These specifications would apply to batteries and flywheels that would be expected to provide both the energy required to meet the "primary energy" range of the vehicle and its maximum power during accelerations. The specifications would be applicable to series and parallel hybrid drivelines, but for specific designs, they could require a slight modification to reflect the detailed control strategy for the engine. In most cases, the modification would reduce the peak power density requirenient; and thus, make the specifications given in Table 4 a conservative requirement. Further, the specifications are also design specific, because they depend on the vehicle performance goals (range and acceleration times) as well as the vehicle design (weight and road load). The approach taken here was to set specifications for "demanding" hybrid designs (short range, fast acceleration performance, and excellent gradeability) with the realization that energy storage devices meeting the specifications in Table 4 could be used with an even higher degree of confidence in "less demanding" vehicle designs.

The specifications for the primary energy storage unit (battery or flywheel) involve both its energy and peak power densities ( $W \cdot h / k g, W \cdot h / L$, $W / \mathrm{kg}, W / L)$. The energy densities $(W \cdot h / k g$ and $W \cdot h / L)$ must be specified at a particular discharge rate, often expressed in terms of the average power density- $(W / \mathrm{kg})$ av-of the discharge. For example, for pure electric vehicles with a relatively long range ( 75 to $100 \mathrm{mi}$ on the FUDS cycle), the average power density for specifying the energy density of batteries for those vehicles is about $10 \mathrm{~W} / \mathrm{kg}$. As shown in Figure 5 (A \& B), for hybrid applications the average discharge power density for a vehicle on the FUDS driving cycle is much higher being 30 to $100 \mathrm{~W} / \mathrm{kg}$ depending on the energy density of the energy storage unit and the "primary energy" range of the hybrid vehicle. Hence, not only are the design specifications for primary energy storage units 
Table 4. Hybrid vehicle energy storage specifications.

\begin{tabular}{|c|c|c|}
\hline \multicolumn{3}{|c|}{$\begin{array}{l}\text { Primary Energy Storage } \\
\text { (no pulse power unit) }\end{array}$} \\
\hline & \multicolumn{2}{|c|}{ (Wh/kg) Primary } \\
\hline & 35 to 45 & 60 to 70 \\
\hline Volumetric energy density $(W \cdot h / L)$ av & 90 & 130 \\
\hline Discharge rate $(W / \mathrm{kg})$ av & 40 & 60 \\
\hline $\begin{array}{l}\text { Peak power } \\
(\mathrm{W} / \mathrm{kg}) \text { FUDS } \\
(\mathrm{W} / \mathrm{kg}) \text { maximum acceleration }\end{array}$ & $\begin{array}{l}250 \\
600 \\
\end{array}$ & $\begin{array}{l}400 \\
900 \\
\end{array}$ \\
\hline Cycle life & 1500 & 1500 \\
\hline $\operatorname{Cost}(\$ / k W \cdot h)$ & 200 & 200 \\
\hline \multicolumn{3}{|c|}{ Pulse Power Unit } \\
\hline & \multicolumn{2}{|c|}{ (Wh/kg) Pulse Unit } \\
\hline & 5 & 10 \\
\hline Volumetric energy density $(W \cdot h / L)$ aver. & 10 & 20 \\
\hline Discharge rate $(\mathrm{W} / \mathrm{kg})$ average & 100 & 200 \\
\hline $\begin{array}{c}\text { Useable peak power } \\
\text { (W/kg) maximum } \\
\text { Efficiency }\end{array}$ & $\begin{array}{r}900 \\
>95 \% \\
\end{array}$ & $\begin{array}{l}1700 \\
>95 \%\end{array}$ \\
\hline $\begin{array}{l}\text { Recharge rate } \\
(W / \mathrm{kg}) \text { average } \\
(W / \mathrm{kg}) \text { maximum }\end{array}$ & $\begin{array}{l}100 \\
400 \\
\end{array}$ & $\begin{array}{l}200 \\
800\end{array}$ \\
\hline Cycle life $e^{c}$ & 100,000 & 100,000 \\
\hline $\operatorname{cost}(\$ / W \cdot h)$ & 1 & 1 \\
\hline \multicolumn{3}{|c|}{$\begin{array}{l}\text { a. Maximum discharge rate at which the useable energy is } 75 \% \text { of that for } \\
\text { discharge at }(\mathrm{W} / \mathrm{kg})_{\text {av }}\end{array}$} \\
\hline \multicolumn{3}{|c|}{ b. Efficiency $=1-I^{2} \cdot R / P_{\max }$ at $(W / k g)_{\max }$} \\
\hline \multicolumn{3}{|c|}{ c. 10-year life, $>100,000 \mathrm{mi}$, discharge/charge at $(\mathrm{W} / \mathrm{kg})_{\text {av }}$} \\
\hline
\end{tabular}




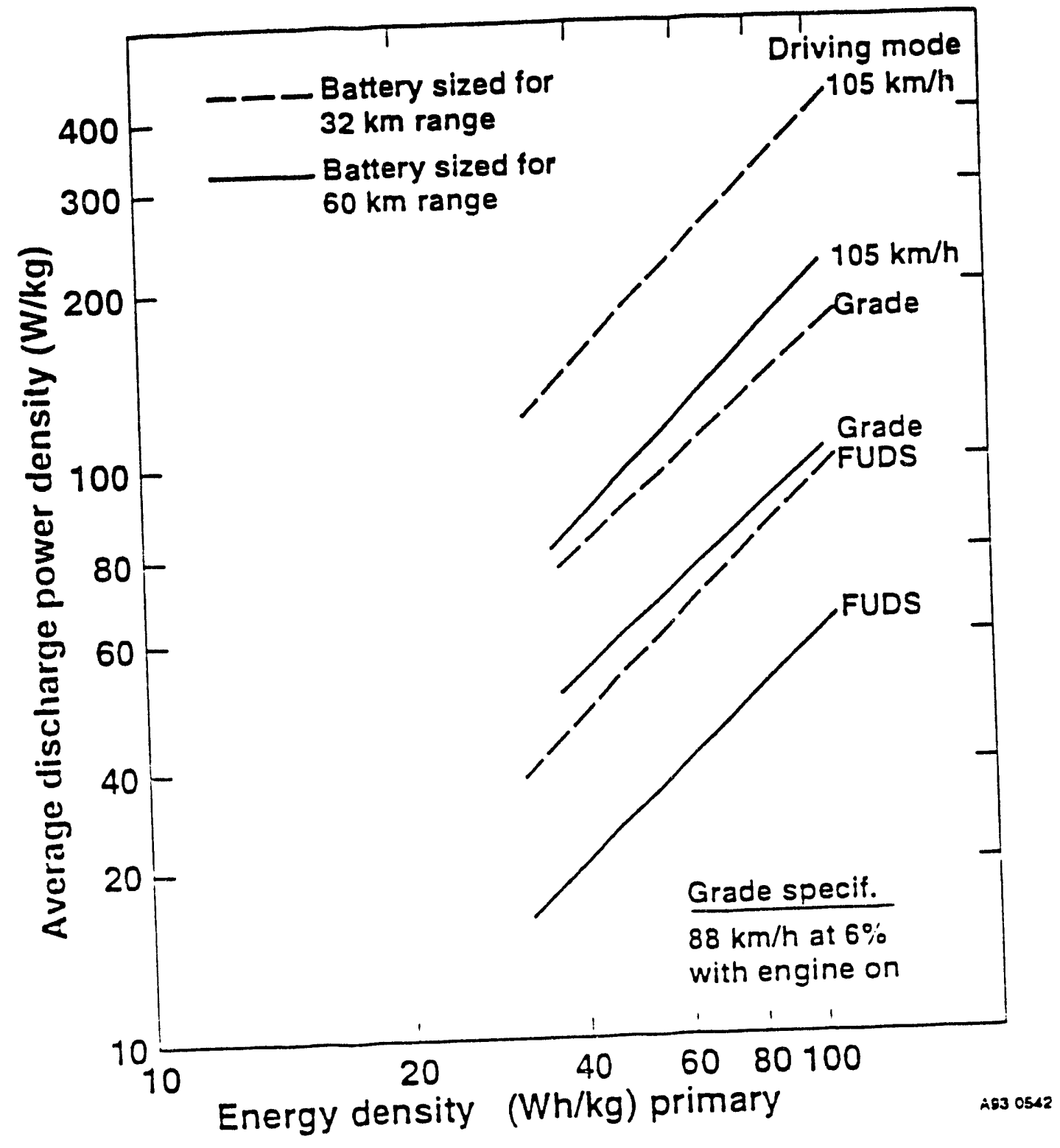

Figure 5-A. Average discharge-power-density for different driving modes for a minivan. 


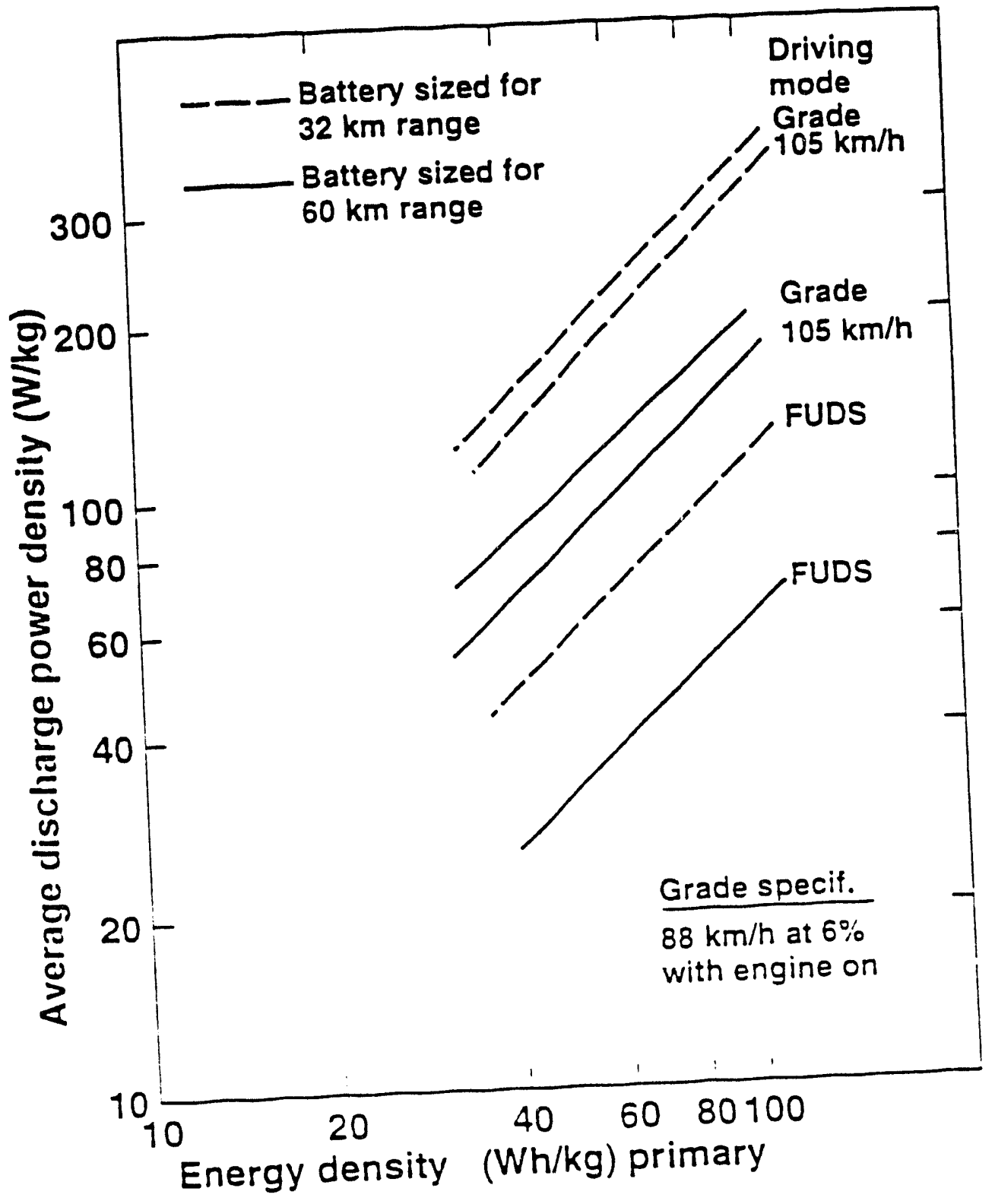

Figure 5-B. Average discharge-power-density for different driving modes for a compact car. 
for hybrid vehicles different than those for pure electric vehicles, the test procedures for determining the performance of the devices will be different than those presently in use for EV batteries.

\section{Pulse Power Energy Storage}

Specifications for pulse power units to be used in hybrid-electric vehicles are also given in Table 4. These specifications would apply to ultracapacitors and other units, such as a flywheel or battery, which are designed to provide the peak power in a hybrid driveline. As indicated in Table 4, the power density specifications of the pulse power unit depend on its energy density and increase as the energy density of the pulse power unit increases. The specifications shown in Table 4 apply to hybrid vehicles having acceleration performance -0 to $60 \mathrm{mph}$ in 10 to 12 seconds- and as in the case of the primary storage unit were set for "demanding" hybrid vehicle designs. A second consideration in specifying the pulse storage unit for a particular application is the energy stored $(w \cdot h)$ in the unit. For the specifications given in Table 4, it was assumed that $500 \mathrm{~W} \cdot \mathrm{h}$ and $750 \mathrm{~W} \cdot \mathrm{h}$ were sufficient energy storage for units to be used in compact cars and minivans, respectively. This energy storage is adequate to load level the battery or engine on the Federal Urban and Highway test cycles and provide pulse power during maximum effort accelerations and passing maneuvers, but it is not adequate to meet the energy requirements for long, steep grades like some found in the Los Angeles Basin, which can require as much as several $\mathrm{kWh}$ (see Table 5).

As shown in Table 6 , the power required to sustain $88 \mathrm{~km} / \mathrm{h}$ ( $55 \mathrm{mph}$ ) on 3 and $6 \%$ grades is relatively high and the length of grade that could be sustained using only the energy stored in the pulse power unit is relatively short $(1.6$ to $2.5 \mathrm{~km})$. For long grades such as those identified in Table 5, the primary storage unit and/or the engine must be used to meet the power 
Table 5. Grades in the Los Angeles Basin and corresponding power and energy requirements at $88 \mathrm{~km} / \mathrm{h}(55 \mathrm{mph})$.

\begin{tabular}{|c|c|c|c|c|c|c|}
\hline \multirow[b]{2}{*}{ Road/Location } & \multirow[b]{2}{*}{$\%$} & \multirow[b]{2}{*}{ Length $(\mathrm{ft})$} & \multicolumn{2}{|c|}{ Power (kH) } & \multicolumn{2}{|c|}{ Energy (kHh } \\
\hline & & & Compact & Minivan & Compact & Minivan \\
\hline $\begin{array}{l}\text { Ventura Freeway } 101 \\
\text { Canejo }\end{array}$ & 7.0 & 8,850 & 30.0 & 43.5 & 0.914 & 1.326 \\
\hline $\begin{array}{l}\text { San Diego Freeway } 405 \\
\text { Mulhauland }\end{array}$ & 4.48 & 7,100 & 22.7 & 34.5 & 0.555 & 0.844 \\
\hline $\begin{array}{l}\text { Highway } 60 \\
\text { Kellog Hill }\end{array}$ & $\begin{array}{l}4.6 \\
3.98 \\
4.83 \\
\end{array}$ & $\begin{array}{l}5,300^{(b)} \\
6,700 \\
3,150 \\
\end{array}$ & $\begin{array}{l}23.3 \\
21.2 \\
24.0 \\
\end{array}$ & $\begin{array}{l}35.0 \\
32.7 \\
36.0 \\
\end{array}$ & $\begin{array}{l}0.423 \\
0.489 \\
0.260 \\
\end{array}$ & $\begin{array}{l}0.639 \\
0.754 \\
0.391 \\
\end{array}$ \\
\hline $\begin{array}{l}\text { Highway } 5 \\
\text { Grapevine }\end{array}$ & 6.0 & 25,600 & 27.3 & 40.5 & 2.407 & 3.570 \\
\hline $\begin{array}{l}\text { Highway } 134 \\
\text { Eagle Rock }\end{array}$ & $\begin{array}{r}4.0 \\
3.73 \\
\end{array}$ & $\begin{array}{l}10,350^{(b)} \\
15,700 \\
\end{array}$ & $\begin{array}{l}21.2 \\
20.5 \\
\end{array}$ & $\begin{array}{l}32.7 \\
31.5 \\
\end{array}$ & $\begin{array}{l}0.756 \\
1.108 \\
\end{array}$ & $\begin{array}{l}1.165 \\
1.703 \\
\end{array}$ \\
\hline
\end{tabular}

Table 6. Power requirements and length of grade sustainable at $88 \mathrm{~km} / \mathrm{h}$ ( $55 \mathrm{mph}$ ) using pulse unit energy storage.

\begin{tabular}{||c|c|c|c|c||}
\hline & \multicolumn{2}{|c|}{ Power Required (kW) } & Length (km/ft) on Pulse Unit \\
\hline Grade (\%) & Compact & Minivan & Compact $^{\text {a }}$ & Minivan $^{\text {b }}$ \\
\hline 3 & 17.5 & 28.3 & $2.5 / 8,200$ & $2.3 / 7,550$ \\
\hline 6 & 27.5 & 40.7 & $1.6 / 5,250$ & $1.6 / 5,250$ \\
\hline a. Pulse unit stores $500 \mathrm{Wh}$ in compact car. \\
\hline b. Pulse unit stores 750 Wh in minivan.
\end{tabular}


requirement on the grade since it is not practical to size the pulse power unit to store the energy (several $\mathrm{kW} / \mathrm{h}$ ) that is needed on those extreme grades. Hence, the gradeability power requirement should be one of the criteria used to size the engine in the hybrid vehicle. 


\section{COMPARISON OF THE SPECIFICATIONS WITH THE CHARACTERISTICS OF VARIOUS ENERGY STORAGE TECHNOLOGIES}

It is of interest to compare the specifications given in Table 4 with the characteristics of various energy storage devices currently available or being developed for use in electric vehicles. The comparisons will be made using a Ragone plot, ${ }^{5}$ which exhibits peak power density- $(\mathrm{W} / \mathrm{kg})$ versus-energy density $(W / \mathrm{h} / \mathrm{kg})$. The power density is calculated from the maximum (peak) useable power from the device for a particular application. The energy density is calculated from the energy stored in the device that can be utilized in the same application. If, for example, as is the case for most batteries, only $20 \%$ of the total energy stored in the device can be used at maximum power, then the usable energy density of the device would be one-fifth of its rated energy density.

The Ragone plot is shown in Figure 6. The specifications for the hybrid vehicle energy storage devices lie on the lines labeled HEV PRIMARY and PULSE. The design goals for the USABC battery program lie on the line labeled USABC. Also shown in Figure 6 are points for monoblock nickel-cadmium and lead-acid batteries, ${ }^{6.7}$ flywheel systems ${ }^{8.9}$ and a bipolar lead-acid batteries. ${ }^{10.11}$ The energy storage unit characteristics fall on three distinct lines showing the difference in the requirements for electric vehicles, hybrid vehicles without a pulse power unit, and hybrid vehicles with a pulse power unit. Also shown on the vertical $\mathrm{W} / \mathrm{kg}$ axis in Figure 6 are the peak power density values for hybrid/electric driveline components. ${ }^{12,13}$ Note that the power density of a state-of-the-art (1993) motor and power electronics/controller unit is significantly higher than that of a engine/transmission unit. ${ }^{14}$ Also note that the power density of the motor/generator/electronics unit projected for the flywheel system ${ }^{8}$ is almost a factor of four higher than that of state-of-the-art motor/electronics units for electric vehicles. 
The program goals for the DOE UItracapacitor Program aro also indicated on Figure 6. Also shown are the characteristics of the Panasonic power capacitors being tested at INEL. ${ }^{15.16}$ All the ultracapacitor results from the previous studies are consistent with the hybrid vehicle energy storage specifications for pulse power units determined in this study. The design goals for the bipolar lead-acid batteries are close to the HEV PRIMARY line for the hybrid vehicles without a pulse power unit. If the high power density of the bipolar battery can be maintained at low states-of-charge, then it would be suitable for use in hybrid vehicles for primary energy storage. If, as is more likely, the power density of the bipolar battery degrades significantly with decreasing state-of-charge, the useable energy density of the battery would be much less than its rated value. In that case, if the bipolar battery were used as a pulse power unit, its power density would be somewhat below the specification line for pulse power units. The "points" for flywheel systems shown on Figure 6 indicate that the characteristics of that system are suitable for use in hybrid vehicles either as a primary energy storage unit or as a pulse power unit. This requires that the energy density of the rotor system (rotor, hub, containment, bearings, etc.) is 40 to $50 \mathrm{~W} \cdot \mathrm{h} / \mathrm{kg}$ and the power density of the motor/generator/electronics is 2 to $3 \mathrm{~kW} / \mathrm{kg}$. It can be concluded from Figure 6 that there are several technologies that have the potential to meet the energy storage specifications for hybrid vehicles. However, none of the technologies have presently been developed to the stage that laboratory tests of even prototype units can be made to verify their performance characteristics. 


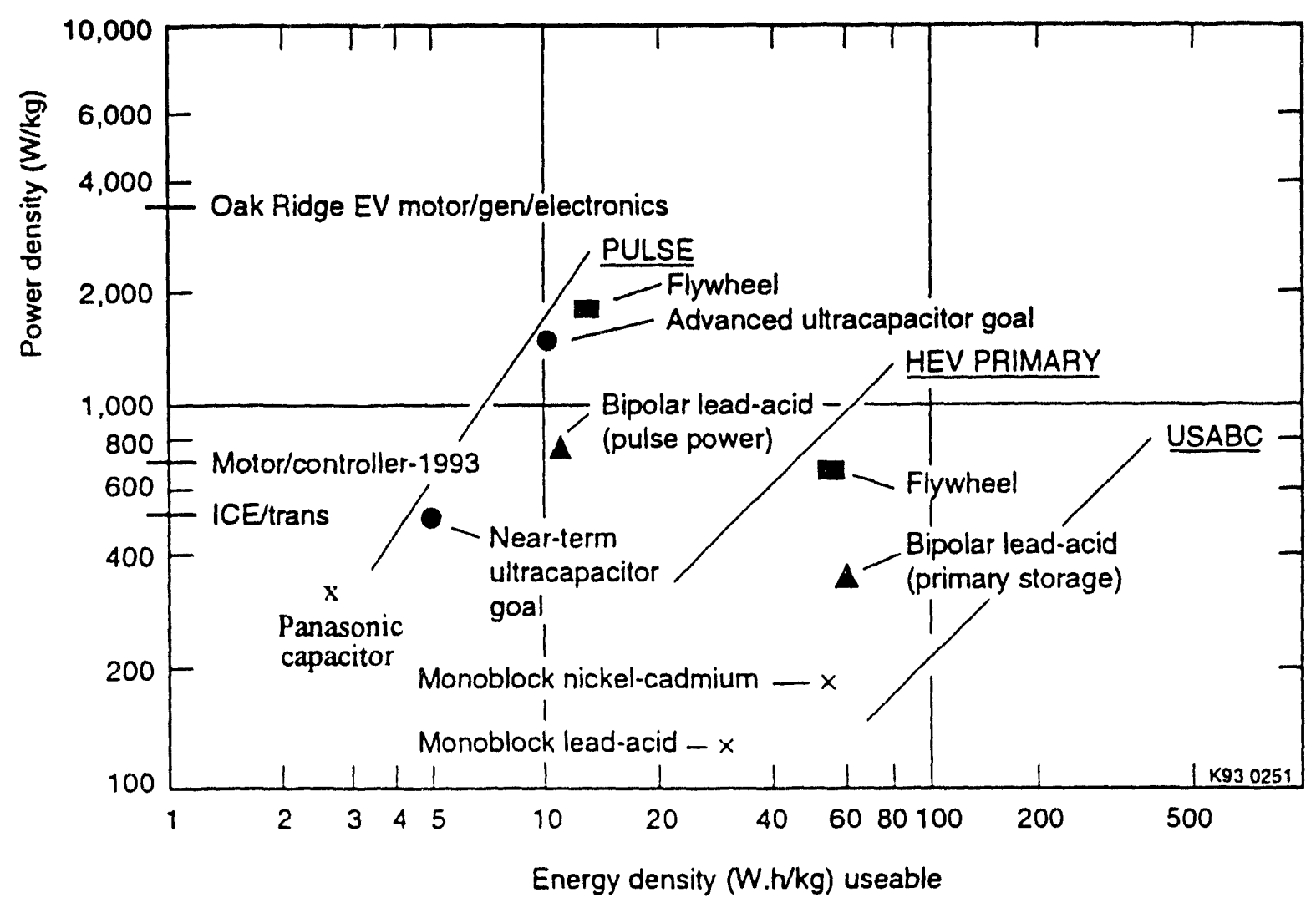

Figure 6. Ragone plot for primary-energy-storage and pulse-power units. 


\section{CYCLE LIFE AND COST CONSIDERATIONS}

Estimates of reasonable cycle life and cost goals can also be made. The cycle life requirement for the primary energy storage unit depends on the use-pattern of the hybrid vehicle and how many years the unit is to last before it is replaced. The USABC goals are five years for the mid-term batteries and ten years for the long-term batteries. Assuming a vehicle range of $50 \mathrm{~km}$ ( 31 miles) on the primary energy storage unit results in about 200 deep discharge cycles per year. For a 5 to 10 year calendar life, the life cycle requirement would be 1000-2000 cycles. The cycle life requirement for primary energy storage devices to be used in hybrid vehicles is about double that for electric vehicles, because the much shorter range of the hybrid vehicle results in more frequent deep discharges of the energy storage unit. The cycle life requirement for a pulse power unit will depend on the frequency of periods of high power demand in urban driving and in the case of the engine-electric hybrid vehicle, in addition the operating strategy for the engine. A recent study ${ }^{17}$ of urban driving indicated that there are four (4) extended periods of high power demand per $12 \mathrm{~km}(7.5 \mathrm{mi})$ of travel. The computer simulation results for an engine-electric vehicle given in Reference 2 showed that the ultracapacitor used in the driveline was discharged/charged five (5) times on the FUDS cycle. These estimates indicate that in urban driving a pulse power unit would be charge/discharge cycled about 0.37 times $/ \mathrm{km}(0.6$ times $/ \mathrm{mi})$. If the unit is to last for $160,000 \mathrm{~km}$ $(100,000 \mathrm{mi})$ in urban driving, the cycle life requirement would be about 60,000 cycles. To account for other eventualities, a cycle 1 ife requirement of 100,000 cycles seems appropriate for the pulse power unit.

Guidance for establishing cost goals for hybrid vehicle energy storage devices will be taken from those given by the USABC for electric vehicle batteries. The USABC mid-term cost goal is $\$ 150 / \mathrm{kW} \cdot \mathrm{h}$ and the long-term goal is $\$ 100 / \mathrm{kW} \cdot \mathrm{h}$. For electric vehicles with a range of $240 \mathrm{~km}$ (150 $\mathrm{mi})$, the long-term cost goal would result in a battery cost of $\$ 2,900$ for a 4-passenger car and $\$ 3,820$ for a minivan. The cost of the energy storage devices in a hybrid vehicle should be limited to a fraction of the battery costs in an 
electric vehicle, because of the need to allow for the cost of the additional components in the hybrid driveline. This should be possible, because of the much shorter range; and thus, the smaller size of the battery in the hybrid vehicle. Recognizing that there is an inherent arbitrariness in selecting cost goals for any development program in its early stages, the costs selected for the hybrid vehicle energy storage units are $\$ 200 / \mathrm{kW} \cdot \mathrm{h}$ for the primary energy storage unit and $\$ 1 / W \cdot h$ for the pulse power unit. For hybrid vehicles with a $46 \mathrm{~km}$ (30 mi) "primary energy" range and 500 to $750 \mathrm{Wh}$ stored energy in the pulse power units, the total cost of the energy storage units would be $\$ 1,100$ for a 4-passenger car and $\$ 1500$ for a minivan with the cost about evenly split between the primary and pulse units for those vehicles having both units. For an engine-electric hybrid vehicle, the cost of the pulse unit would be $\$ 500$ to $\$ 1,000$ depending on its size. All of these costs for the energy storage units for hybrids are well below those for electric vehicles even though the specific costs $(\$ / k W \cdot h)$ for the units are higher than the USABC goals for batteries for electric vehicles. 


\section{CONCLUSIONS}

A study has been made of energy storage unit requirements for hybrid-electric vehicles. The powertrains for these vehicles included both primary energy storage units and/or pulse power units. The primary energy storage units were sized to provide "primary energy" ranges up to $60 \mathrm{~km}$ $(38 \mathrm{mi})$. The total power capability of the powertrains were such that the vehicles had 0 to $96 \mathrm{~km} / \mathrm{h}(0$ to $60 \mathrm{mph}$ ) acceleration times of 10 to $12 \mathrm{~s}$. One of the prime objectives of the study was to determine the power density requirements for the energy storage devices such that they could be used in these high performance hybrid vehicle applications. The results of the study are displayed as a Ragone plot ( $W / \mathrm{kg}$ )-peak power density-versus-useableenergy - density ( $W \cdot h / k g)$-for energy storage systems used as primary energy storage or pulse power.

In general, the power density requirements for primary energy storage devices to be used in hybrid vehicles are much higher (nearly an order of magnitude for a given energy density) than that for devices to be used in electric vehicles. The energy density and power density requirements for pulse power devices for hybrid vehicles, including engine-electric vehicles, are not much different than those to be used to load-level the battery in an electric vehicle.

The cycle life requirements $(1,000$ to 2,000) for primary energy storage units for hybrid vehicles are about double that for electric vehicles, because of the reduced size of the storage units in the hybrid vehicles. The cycle life requirement of 100,000 for pulse power devices for hybrid vehicles is about the same as for electric vehicles having battery load leveling.

The cost of the energy storage units in hybrid vehicles should be much less (at least a factor of two) than those in all-electric vehicles. This will be the case if the specific cost of the primary energy storage units is $\$ 200 / \mathrm{kW} \cdot \mathrm{h}$ and that of the pulse power unit is $\$ 1 / \mathrm{W} \cdot \mathrm{h}$. 
There are no presently available energy storage units that meet all the requirements for hybrid vehicle applications, but ultracapacitors and bipolar lead-acid batteries are under development that have the potential for meeting them if the program design goals are met. If flywheel systems having a mechanical system (rotor, bearings, containment) energy density of 40 to 50 $\mathrm{Wh} / \mathrm{kg}$ and an electrical system power density of 2 to $3 \mathrm{~kW} / \mathrm{kg}$ can be developed, the flywheel system also would have the potential of meeting the hybrid vehicle energy storage unit requirements. System costs for both the ultracapacitor and flywheel units are uncertain at the present time, but their costs will ultimately be key factors in determining their applicability in hybrid vehicle drivelines. 


\section{REFERENCES}

1. Burke, A.F., Hybrid/Electric Vehicle Design Options and Evaluations, SAE Paper 920447, SAE International Congress \& Exposition, Detroit, Michigan, February 1992

2. Burke, A.F., On-Off Engine Operation for Hybrid-Electric Vehicles, SAE Paper 930042, SAE International Congress \& Exposition, Detroit, Michigan, March 1993

3. Cole, G.H., SIMPLEV: A Simple Electric Vehicle Simulation ProgramVersion 1, EG\&G Report DOE/ID-10293, June 1991

4. Burke,A.F. and Cole, G.H., Simulation of Electric Vehicles with Hybrid Power Systems, 10th International Electric Vehicle Symposium, Hong Kong, December 1990

5. Heitner, K., Private Communication Regarding a Generalized Ragone Plot, May 1993

6. Hardin, J.E., Laboratory Testing of SAFT SEH-5-200 6 Volt Traction Battery, EG\&G Report EGG-EP-8917, December 1989

7. Hardin, J.E., Laboratory Testing of Sonnenschein DF6V180 6 Volt Traction Battery, EG\&G Report EGG-EP-8656, July 1989

8. Coyner, J.V., Flywheel Energy Storage and Power Electronics Programs, presentation at Oak Ridge National Laboratory, May 1993

9. Comfort, W.J. etals, Feasibility Assessment of Electromechanical Batteries for Electric Vehicles, Lawrence Livermore National Laboratory, Report No. UCRL-ID 109422, May 1992

10. Rowlette, J.J. and Harbaugh, D.L., Battery Goals for EV Hybrid, Proceedings of the Seventh Annual Battery Conference on Applications and Advances, Cal ifornia State University at Long Beach, January 1992

11. Rowlette, J.J. and Harbaugh, D.L., Matching Electric Vehicle Battery Performance to User Needs, SAE Paper 920832, SAE International Congress \& Exposition, Detroit, Michigan, February 1992

12. Burke, A.F., Electric Vehicle Propulsion and Battery Technology 1975-1995, Proceedings of the 25th Intersociety Engineering Conference on Energy Conversion, Reno, Nevada, August 1990

13. Cole, G.H., Comparison of the Unique Mobility and DOE-Developed AC Electric Drive Systems, EG\&G Report DOE/ID-10421, January 1993.

14. Bentley, M.B. etals, The Impact of Electric Vehicles on $\mathrm{CO}_{2}$ Emissions, EG\&G Report EGG-EP-10296, May 1992. 


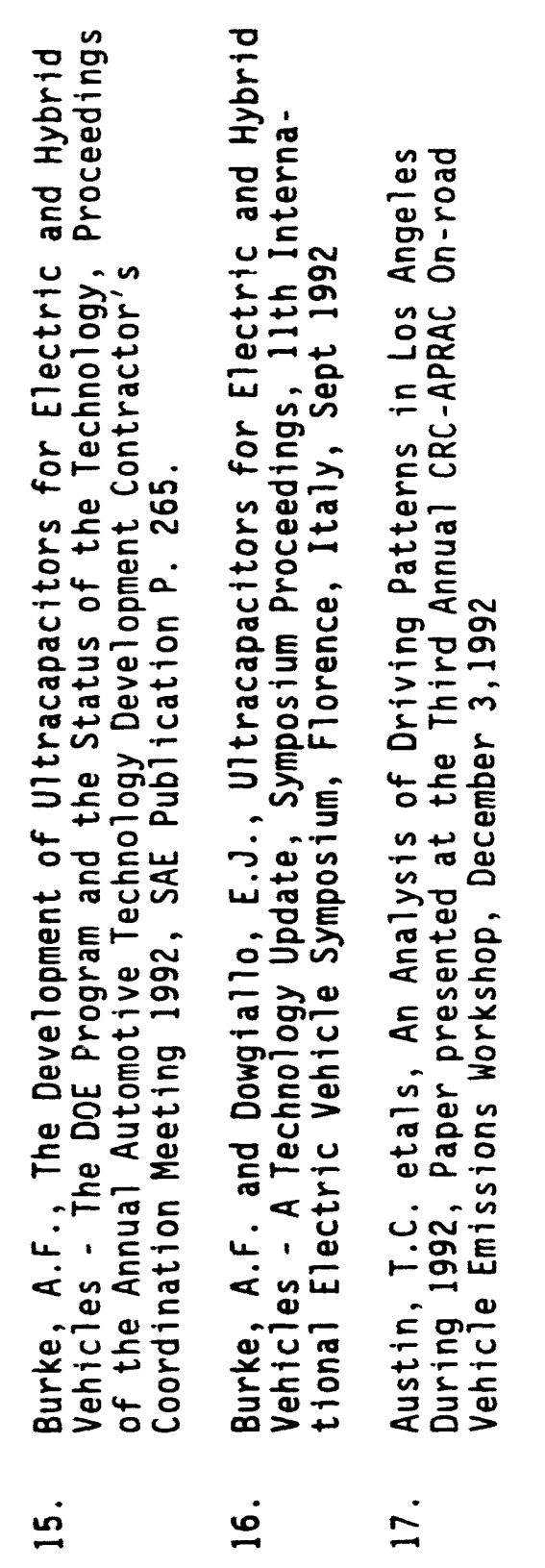




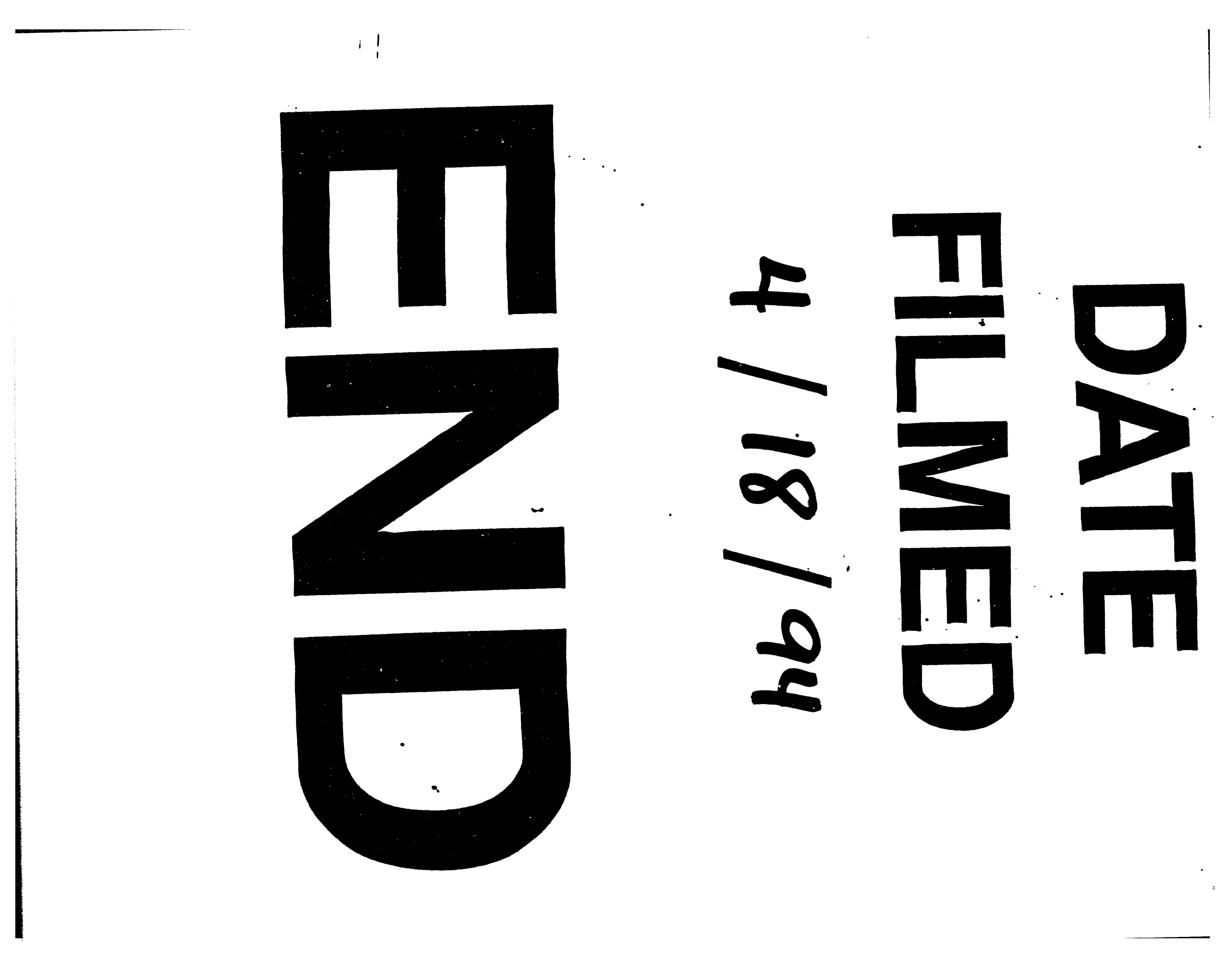


